\title{
Aortic valve repair by sinotubular junctional remodeling to eliminate aortic regurgitation in donor cardiac allograft
}

\author{
David J. Kaczorowski, MD, and Y. Joseph Woo, MD, Philadelphia, Pa
}

Donor hearts for cardiac transplantation are scarce resources and their availability limits the number of heart transplants performed annually. When feasible, repairing donor hearts allows maximal use of these resources. Valvular heart disease has previously been considered a contraindication to use of a donor heart. However, several centers have reported use of donor hearts with aortic valve disease. Back bench aortic valve replacement has been used in donor hearts with a bicuspid aortic valve and aortic stenosis. ${ }^{1,2}$ Subcommissural annular plication has been used to correct aortic insufficiency (AI) in a heart with an aortic

From the Division of Cardiovascular Surgery, University of Pennsylvania, Philadelphia, Pa.

Disclosures: Authors have nothing to disclose with regard to commercial support. Received for publication Feb 6, 2012; accepted for publication March 12, 2012; available ahead of print April 9, 2012.

Address for reprints: Y. Joseph Woo, MD, Division of Cardiovascular Surgery, University of Pennsylvania, 3400 Spruce St, 6 Silverstein Pavilion, Philadelphia, PA 19104 (E-mail: joseph.woo@uphs.upenn.edu).

J Thorac Cardiovasc Surg 2012;144:722-4

$0022-5223 / \$ 36.00$

Copyright (C) 2012 by The American Association for Thoracic Surgery

http://dx.doi.org/10.1016/j.jtcvs.2012.03.011 valve that was normal with the exception of annular dilatation. $^{3}$

AI can develop in the setting of sinotubular junction (STJ) dilatation with an enlarged ascending aorta. When the valve is trileaflet, the cusps are frequently normal and correction of the STJ dilatation alone can ameliorate $\mathrm{AI}^{4}{ }^{4}$ Repair of structurally normal aortic valves via remodeling of the STJ has yielded excellent outcomes with outstanding durability of repaired valves. In 1 series, freedom from reoperation was $100 \%$ at 7 years and freedom from AI (>2+) was $87 \%$ at 5 years. ${ }^{4}$ In another series of 103 consecutive patients, freedom from moderate or severe AI was $80 \%$ at 10 years and freedom from reoperation was $97 \%$ at 10 years. ${ }^{5}$ Herein we report a technique for remodeling the STJ of a donor heart to successfully eliminate AI.

\section{TECHNIQUE}

A 56-year-old man with nonischemic cardiomyopathy was listed for transplantation. A donor heart became available. The donor was a 63-year-old woman in whom an

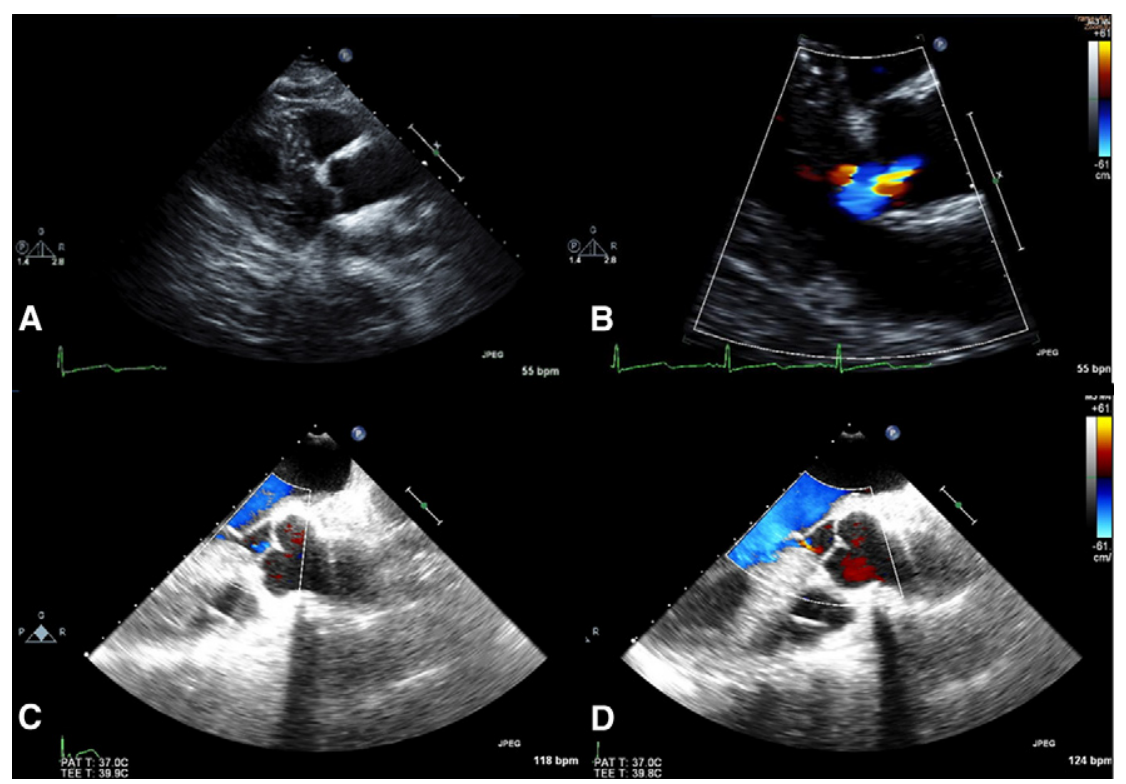

FIGURE 1. Echocardiographic assessment of the donor heart before procurement and after completion of sinotubular junctional aortic valve repair. A, Two-dimensional echocardiography of the donor revealed a dilated ascending aorta. B, Echocardiography with color flow revealed central aortic regurgitation in the presence of a structurally normal aortic valve in the donor heart. C, Intraoperative transesophageal echocardiogram with color flow of the transplanted heart with newly remodeled sinotubular junction demonstrating excellent aortic valve leaflet coaptation and trivial aortic regurgitation. $\mathrm{D}$, Alternative view the transplanted heart with the newly remodeled sinotubular junction. 


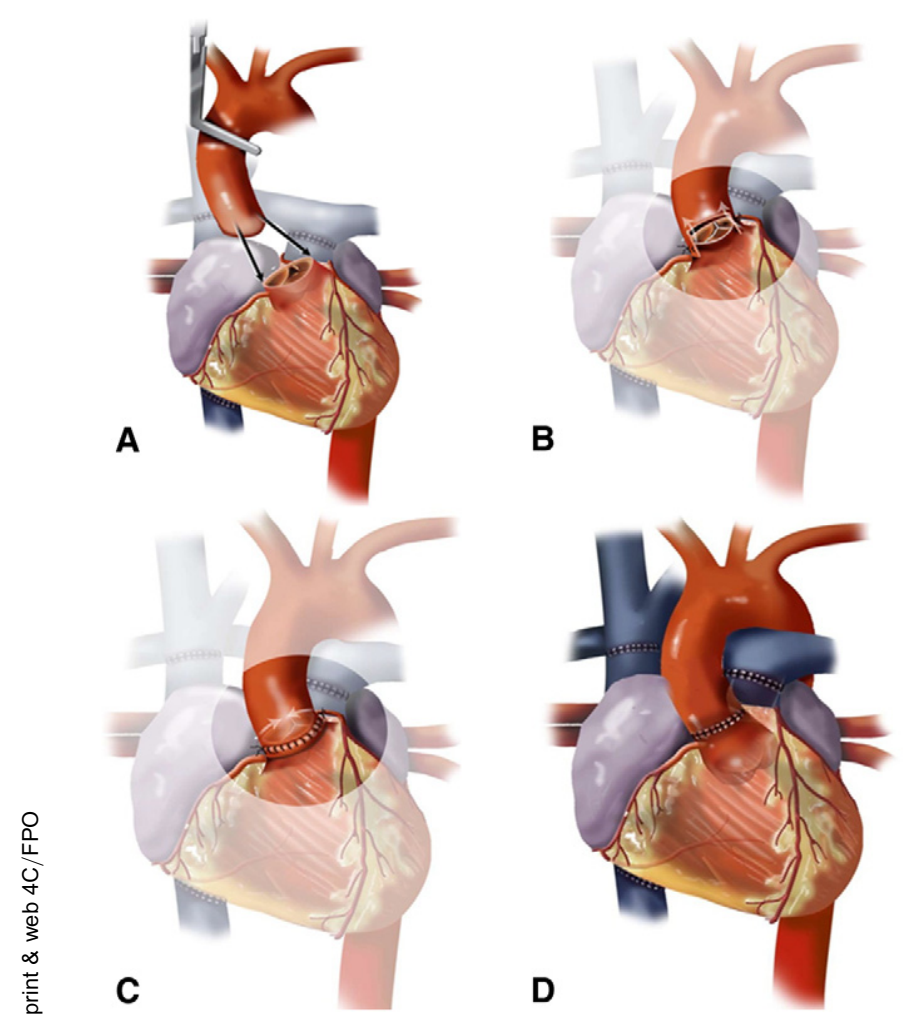

FIGURE 2. Sinotubular junctional aortic valve repair of the donor heart. A, Preservation of the entire recipient aorta and resection of the donor aorta to the level of the sinotubular junction. B, The donor aorta is intussuscepted into the recipient aorta during construction of the aortic anastomosis, resulting in improved aortic valve leaflet coaptation. $\mathrm{C}$, The newly remodeled sinotubular junction. D, The transplanted heart after completion of all anastomoses.

intracranial hemorrhage had resulted in brain death. A transthoracic echocardiogram revealed that the donor heart had mild to moderate central aortic regurgitation in the setting of a dilated ascending aorta measuring roughly $3.9 \mathrm{~cm}$ with a structurally normal trileaflet aortic valve and preserved biventricular function (Figure 1, $A$ and $B$ ). The heart was accepted for transplant. External manual pressure was applied to the aortic root to avoid aortic regurgitation during delivery of cardioplegic solution. In addition to venting the heart via the inferior vena cava and left atrial appendage, we also vented the left atrium directly to allow manual crossing of the mitral valve to prevent distention of the left ventricle. Otherwise, standard preservation techniques were used.

For the recipient operation, a median sternotomy was performed. Bicaval and aortic cannulation was used for cardiopulmonary bypass. The recipient cardiectomy was performed in a routine manner. The left atrial, inferior vena caval, superior vena caval, and pulmonary artery anastomoses were performed in a standard fashion.

A specific strategy was used to manage the aortic regurgitation during implantation. The recipient aorta, which was of a normal caliber, was preserved for nearly its entire length (Figure 2, $A$ ). The donor aorta was resected down to the level of the STJ (Figure 2, $A$ ). The aortic anastomosis was created in an intussuscepting fashion of donor aorta into the normal caliber native aorta (Figure 2, B). Doing so allowed the donor STJ to be remodeled for improved aortic valve leaflet coaptation (Figure 2,C).

After completion of the aortic anastomosis (Figure 2, $D)$, the heart was allowed to reperfuse and cardiopulmonary bypass was withdrawn without difficulty. A transesophageal echocardiogram revealed excellent aortic valve leaflet coaptation with trivial aortic regurgitation (Figure 1, $C$ and $D$ ) and hyperdynamic biventricular function. The patient recovered well postoperatively without complication and was discharged to his home. At most recent follow-up, an echocardiogram revealed hyperdynamic left ventricular function with trace AI.

\section{DISCUSSION}

Use of STJ aortic valve repair yielded an excellent outcome in this case. Ongoing echocardiographic surveillance will be used to monitor for the development of recurrent AI. However, the results of STJ aortic valve repair in the setting of ascending aortic aneurysm repair have demonstrated excellent durability. ${ }^{4,5}$ On the basis of this observation, acceptable durability would also be expected in this case.

One advantage of the STJ repair as described here is that no additional time is required to perform this type of repair. Careful assessment of the aortic valve and the etiology of AI in the donor heart is essential. If there is intrinsic valvular disease, repair may be more complicated, which may add to the duration of ischemic time. Further, if intrinsic valvular disease is present, valve repair may be less durable.

Repairing donor hearts when possible allows maximal use of these scarce resources. This case demonstrates that aortic valve repair with STJ remodeling can be used to mitigate aortic regurgitation in the donor heart in the setting of aortic regurgitation with a structurally normal aortic valve with excellent results.

\section{References}

1. Larobina ME, Mariani JA, Rowland MA. Aortic valve replacement for aortic stenosis during orthotopic cardiac transplant. Ann Thorac Surg. 2008;86: 1979-82.

2. Saito S, Matsumiya G, Ueno T, Sakaguchi T, Kuratani T, Ichikawa H, et al. Bench replacement of donor aortic valve before orthotopic heart transplantation. J Heart Lung Transplant. 2009;28:981-3. 
3. Navia JL, Atik FA, Marullo A, Starling RC, Garcia M, Vega PR, et al. Bench repair of donor aortic valve with minimal access orthotopic heart transplantation. Ann Thorac Surg. 2005;80:313-5.

4. Boodhwani M, de Kerchove L, Glineur D, Rubay J, Vanoverschelde JL, Van Dyck M, et al. Aortic valve repair with ascending aortic aneurysms: associated le- sions and adjunctive techniques. Eur J Cardiothorac Surg. 2011;40:424-8. Epub 2011 Jan 13.

5. David TE, Feindel CM, Armstrong S, Maganti M. Replacement of the ascending aorta with reduction of the diameter of the sinotubular junction to treat aortic insufficiency in patients with ascending aortic aneurysm. J Thorac Cardiovasc Surg. 2007;133:414-8.

\title{
Surgical cryoablation for ventricular tachyarrhythmia in patients undergoing surgical ventricular restoration: Lessons learned from radiofrequency ablation
}

\author{
Rao V. Parachuri, FRCS(Cth), ${ }^{\mathrm{a}}$ and Srilakshmi M. Adhyapak, DNB, ${ }^{\mathrm{b}}$ Bangalore, India
}

With the limited number of available donor hearts, therapeutic options are limited even for those patients who are eligible for transplantation. The clinical presentation of patients with post-myocardial infarction left ventricular aneurysms is usually heart failure, angina, or ventricular tachyarrhythmia. In patients with ventricular tachyarrhythmia, the role of adjuvant arrhythmia surgery during surgical ventricular restoration is unquestionable. In patients who do not present with arrhythmia, however, the role of preoperative electrophysiologic testing to demonstrate inducibility of such arrhythmia is not clear.

The concomitant surgical procedures for arrhythmia in the late 1970s and early 1980s included map-guided or unguided endocardectomy and encircling cryoablation of the border zone. These procedures targeted ablation of ventricular tachyarrhythmia caused by reentrant circuits that were presumed to exist in the border zone. ${ }^{1}$ In the 1990 s, computer modeling, animal studies, and human studies demonstrated that such circuits contain a narrow isthmus of viable tissue and slow conduction that forms a critical part of the ventricular tachyarrhythmia reentrant circuit and is bound by infarcted tissue or anatomic barriers, such as the mitral valve annulus. ${ }^{2,3}$ Radiofrequency ablation is targeted at

From the Division of Cardiovascular Surgery, University of Pennsylvania, Philadelphia, Pa.

Disclosures: Authors have nothing to disclose with regard to commercial support.

Received for publication Jan 10, 2012; revisions received Jan 30, 2012; accepted for publication March 12, 2012; available ahead of print April 9, 2012.

Address for reprints: Srilakshmi M. Adhyapak, DNB, c/o V. Rao Parachuri, FRCS(Cth), Narayana Hrudayalaya Institute of Medical Sciences; 258/A, Bommasandra Industrial Area, Anekal Taluk, Bangalore 560099, India (E-mail: srili2881967@yahoo.com).

J Thorac Cardiovasc Surg 2012;144:724-6

$0022-5223 / \$ 36.00$

Copyright (c) 2012 by The American Association for Thoracic Surgery

http://dx.doi.org/10.1016/j.jtcvs.2012.03.023

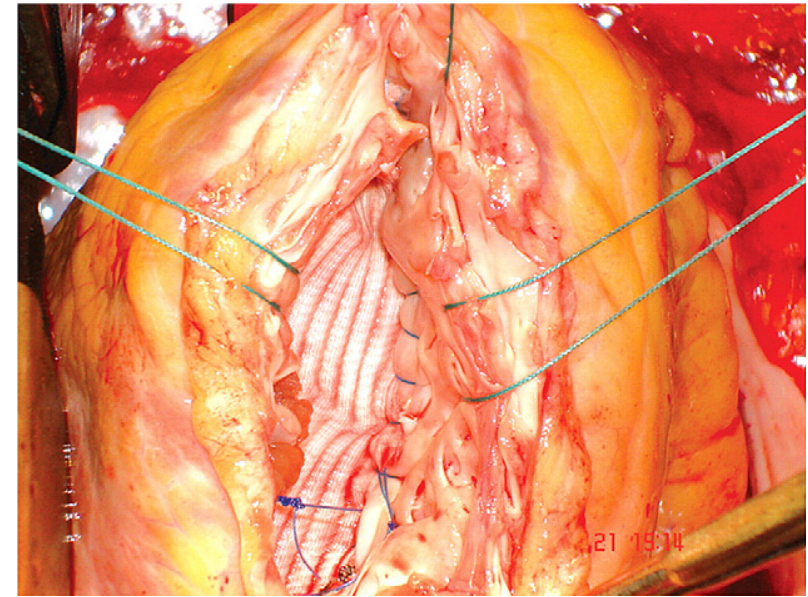

FIGURE 1. Linear endoventricular patch used to exclude the infarcted myocardium. (Reprinted with permission from Parachuri VR, Adhyapak SM, Kumar P, Setty R, Rathod R, Shetty DP. Ventricular restoration by linear endoventricular patchplasty and linear repair. Asian Cardiovasc Thorac Ann. 2008;16:401-6.)

ablating this isthmus to abolish the reentrant mechanism of ventricular tachyarrhythmia. This procedure is usually performed after mapping the isthmus by 3-dimensional cartography. Surgical mapping of the reentrant circuit is cumbersome, however, and we therefore modeled our cryoablation technique from available data on the anatomic location of the isthmus. We now evaluate the midterm results of surgical linear cryoablation of ventricular tachyarrhythmia in patients undergoing surgical ventricular restoration.

\section{CLINICAL SUMMARY}

We performed linear cryoablation in 6 patients presenting with spontaneous ventricular tachyarrhythmia who were 